wound in consequence of a web of skin, like that of a dog's dew claw, was some inches in length), and then sutured with catgut, except at the dependent part of the wound (I used no drainage tube). I then dressed with iodoform and wood-wool and applied a calico bandage ; subsequently the dressing was changed daily, using, however, iodoform and boracic acid together.

Nearly the whole wound united by first intention, but just over the joint, for about $\frac{3}{4}$ of an inch, a very obstinate place healed by granulation. I used iodine I, glycerine 8 ; also painted with mercuric chloride solution, I in IOOO; then on the 28 th I blistered all round the leg, as, do what I would, an obstinate firm gelatinous exudate formed over this small place and prevented healing. On this day, viz., I $9^{\text {th }}$ September, I am pleased to say that the wound is quite healed, and there is a good growth of hair under the scaling epidermis and dried exudate. The leg itself is no bigger than its fellow, except over the inferior epiphysis of the small internal metacarpal. The bones of the extra digit are shown in Fig. 5, Plate X. The upper of the two small bones is a sesamoid, and the lower the navicular.

The first phalanx is a little over 2 inches long, the second phalanx is rather more than $1 \frac{1}{4}$ inch in length, and the third phalanx is $I$ inch from the pyramidal process to toe, which, as the illustration will show, is pointed. The navicular bone is $\frac{7}{8}$ of an inch in length. The inside of the hoof was perfect; outside the frog was rudimentary. Before the operation the point of hoof was $2 \frac{1}{2}$ inches from the ground, and above the coronet the circumference of the digit was 7 inches.

It will be noticed that the photographs represent the extra digit as being on the outside of the limb (off), but that is owing to the figures having been reversed in the process of printing.

\title{
IMPERFECT SUPERNUMERARY DIGIT IN A HORSE.
}

By E. Shave, M.R.C.V.S., Royal Veterinary College, London.

IN Plate X., Figs. I and 2 represent respectively the back and front views of the metacarpal bones of the right limb of a horse, and show the very unusual size of the internal metacarpal bone $(b)$, which is anchylosed to the principal bone $(a)$, except at its two extremities. The shaft of this bone measures $9 \frac{1}{2}$ inches in length, and has an average diameter of $I \frac{1}{4}$ inch; the upper extremity measures $\mathrm{I} \frac{3}{8}$ inch laterally, and $\mathrm{I} \frac{1}{2}$ inch from before backwards, and it is covered with articular cartilage. The inferior extremity is also covered by articular cartilage, and presents a median ridge, 2 inches from before backwards; this separates two slightly convex condyles, the inner of which is the larger. Articulating with this extremity was a small triangular bone (c), the wide superior extremity of which closely resembles the upper end of the ordinary proximal phalanx; it measures $2 \frac{1}{4}$ inches from side to side, $I \frac{1}{4}$ inch from before backwards, and $1 \frac{5}{8}$ inch in length.

The principal and outer small metacarpal bones show no special point of interest.

The specimen was kindly given to me by $\mathrm{Mr}$ William Shaw, F.R.C.V.S. Unfortunately we could not obtain the bones of the carpus, nor any history or facts concerning the appearance of the animal during life. 

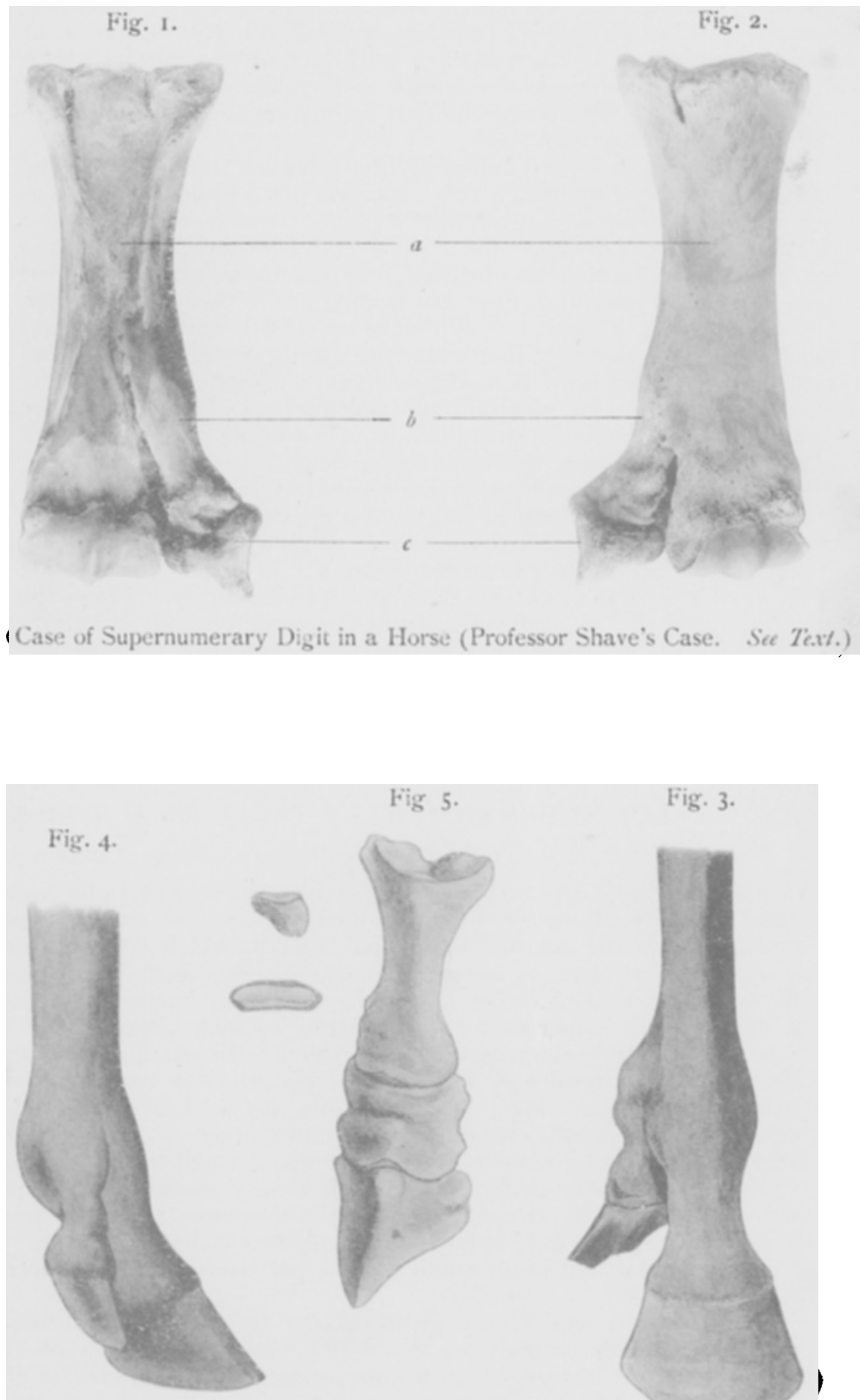